\title{
Aripiprazole Versus Lithium in Management of Acute Mania: a Randomized Clinical Trial
}

\author{
SS Shafti
}

\begin{abstract}
Objective: This study aimed to compare aripiprazole with lithium for the effectiveness of treating Iranian male patients with acute mania.

Methods: A total of 30 male in-patients with bipolar I disorder who presented with relapse or new emergence of an episode of acute mania were equally randomised to receive 4 weeks of aripiprazole $(5 \mathrm{mg}$ uncoated tablets) or lithium carbonate (300 mg uncoated tablets) according to standard practice guidelines and titration protocols. The Manic State Rating Scale (MSRS) was used to determine the severity of manic symptoms at baseline (week 0) and up to week 4. The Bech-Rafaelsen Mania Scale (BRMS), Schedule for Assessment of Insight (SAI), and Clinical Global Impressions-Global Improvement scale (CGI-G) were used to determine the severity of manic symptoms, insight, and overall illness severity, respectively. All outcome measures were recorded by a single experienced psychiatrist.

Results: The frequency and intensity of manic symptoms (MSRS score) in both groups decreased significantly from baseline to week 4 . In the aripiprazole and lithium groups, the intensity of manic symptoms decreased by $\geq 25 \%$ in 5 and 7 patients and by $>50 \%$ in 1 and 5 patients, respectively. Betweengroup analysis showed that lithium was more effective at weeks 3 and 4 in decreasing the frequency and intensity of manic symptoms. The lithium group achieved greater improvement in symptoms than the aripiprazole group in terms of BRMS score, SAI score, and CGI-G.

Conclusion: Lithium is more effective than aripiprazole in improving manic symptoms.
\end{abstract}

Key words: Aripiprazole; Bipolar disorder; Lithium

Dr Saeed Shoja Shafti, MD, Professor of Psychiatry, University of Social Welfare and Rehabilitation Sciences, Razi Psychiatric Hospital, Tehran, Iran.

Address for correspondence: Dr Saeed Shoja Shafti, MD, Professor of Psychiatry, University of Social Welfare and Rehabilitation Sciences, Razi Psychiatric Hospital, Tehran, Iran. Postal code: 18669-58891. PO Box: 18735569.

Tel: 0098-21-33401220; Fax:0098-21-33401604; Email: ssshafti@gmail.com

Submitted: 24 July 2017; Accepted: 6 March 2018

\section{Introduction}

Bipolar disorder is characterised by incidents of irritable or elevated mood (hypomanic or manic episodes) and periods of loss of energy and low mood (depressive episodes). ${ }^{1}$ Its incidence in the United States is estimated to be $0.6 \%$ per year. Similarly, the prevalence of bipolar I disorder across 11 nations ranges from $0 \%$ to $0.6 \%$ per year. $^{2}$ The necessary feature of a manic episode is that there is an abnormally irritable, elevated, or expansive mood, and increased energy or activity lasting at least 1 week (or any duration if hospitalisation is necessary), along with at least 3 symptoms from Criterion B (grandiosity, short sleep, pressure of speech, flight of ideas, distractibility, hyperactivity, or excessive involvement in risky activities). ${ }^{2}$ Serious consequences of a manic episode often result from loss of insight, hyperactivity, and poor judgement. ${ }^{2}$ The lifetime risk of suicide in individuals with bipolar disorder is estimated to be at least 15 times that of the general population; suicide in individuals with bipolar disorder may account for one-quarter of all completed suicides. ${ }^{2}$ Compared with the late-onset form, early-onset bipolar disorder results in graver psychosociological consequences and is characterised by rapid cycling and increased risks of suicide attempts and substance abuse. ${ }^{3}$

Pharmacotherapy is the treatment of choice for acute mania, with the goal of rapid control of dangerous behaviour, aggression, and agitation. The use of lithium has been limited in recent years owing to its adverse effects and necessity for frequent laboratory tests. First-generation antipsychotic agents (such as haloperidol) and secondgeneration antipsychotics (such as aripiprazole, clozapine, olanzapine, quetiapine, risperidone, and ziprasidone) are widely used in the treatment of bipolar disorder. ${ }^{4,5}$ Aripiprazole is increasingly used for controlling acute manic and mixed episodes of bipolar I disorder ${ }^{6,7}$ and for maintenance treatment of bipolar disorder. ${ }^{8}$ It is safe and effective as an adjunctive to either valproate or lithium. ${ }^{9}$ It can also be used for management of psychiatric disorders. Aripiprazole is a partial agonist to dopamine D2 and D3, and serotonin 5-HT1A, and exhibits antagonistic action at 5-HT2A and $\mathrm{H} 1$ receptors. ${ }^{6,7}$ These properties may explain obvious differences in tolerability profiles of aripiprazole when compared with those of first-generation antipsychotics. ${ }^{10}$ 
Aripiprazole is associated with sedation, weight gain, and extrapyramidal symptoms. Nonetheless, one study reported comparable incidence of extrapyramidal symptoms over 12 weeks between aripiprazole $(10 \mathrm{mg} /$ day $)$ and placebo. ${ }^{10}$ Aripiprazole (15-30 mg/day) achieved substantial amelioration of acute mania, the extent of which was comparable to that achieved by lithium. ${ }^{11}$ Aripiprazole monotherapy (15-30 mg/day) appeared to be as effective as lithium (900-1500 mg/day) for extended treatment of mixed or manic episodes. ${ }^{12}$ On the basis of existing guiding principles, aripiprazole is considered a first-line alternative for the short-term management of mania. ${ }^{7}$ However, comparative studies of aripiprazole and other mood stabilisers are scarce. ${ }^{1,13}$ Thus, this study aimed to compare aripiprazole with lithium for the effectiveness of treating Iranian male patients with acute mania.

\section{Methods}

This study was approved by the ethics committee of Razi Psychiatric Hospital, Iran. Informed consent was obtained from each patient or his legal representative. A total of 30 male in-patients with bipolar I disorder who were admitted to Razi Psychiatric Hospital owing to relapse or new emergence of an episode of acute mania were equally randomised to receive 4 weeks of aripiprazole $(5 \mathrm{mg}$ uncoated tablets) or lithium carbonate (300 mg uncoated tablets) according to standard practice guidelines and titration protocols. Patients were excluded if they had mixed episodes, suicidal ideation, severe instability or aggression, substance abuse, neurological and other severe medical illnesses, or previous treatment with antidepressants or long-acting antipsychotics (depot administration).

The patients, staff, and assessor were blinded to the prescribed drugs, which had been packed into identical capsules. Prescription of lorazepam as a sedating agent was permissible. No other anticonvulsant or supplementary antipsychotic was allowed. No additional psychosocial intervention such as psychotherapy was allowed. Respectively in the aripiprazole and lithium groups, the mean \pm standard deviation (SD) daily dosage was $25.83 \pm 4.93$ $\mathrm{mg} /$ day and $981.81 \pm 161.34 \mathrm{mg} / \mathrm{day}$, whereas the mean \pm SD dosage of adjunctive lorazepam was $4.50 \pm 1.11 \mathrm{mg} /$ day and $4.18 \pm 0.93 \mathrm{mg} /$ day $(t=0.746,95 \%$ confidence interval $[\mathrm{CI}]=-0.57$ to $1.21, \mathrm{p}<0.46)$. The mean \pm SD serum level of lithium was $0.80 \pm 0.15$ milliequivalents per litre.

The Manic State Rating Scale (MSRS) was used to determine the severity of manic symptoms at baseline (week 0) and up to week 4. It has 26 items, each of which has a frequency score of 0 to 5 and an intensity score of 1 to 5. Inter-rater reliability for each item has been reported to be 0.89 to $0.99 .{ }^{14}$ In addition, the Bech-Rafaelsen Mania Scale (BRMS) ${ }^{15}$ Schedule for Assessment of Insight (SAI), ${ }^{16}$ and Clinical Global Impressions-Global Improvement scale $(\mathrm{CGI}-\mathrm{G})^{17}$ were used to determine the severity of manic symptoms, insight, and overall illness severity, respectively. All outcome measures were recorded by a single experienced psychiatrist.

The 2 groups were compared using the $t$ test for baseline characteristics and MSRS scores. The repeated-measures analysis of variance (ANOVA) was used for within-group analysis, and the split-plot (mixed) design ANOVA was used for between-group analysis. BRMS, SAI, and CGI-G scores at baseline and week 4 were compared using the $t$ test. Cohen's effect size was measured to determine the strength of effectiveness, and the power of the study (posthoc) was evaluated to determine the type II error. A p value of $<0.05$ was considered statistically significant. MedCalc Statistical Software version 15.2 (https://www.medcalc.org) was used.

\section{Results}

Three patients in the aripiprazole group and four patients in the lithium group dropped out from the study owing to unwillingness to participate or adverse effects of the prescribed drugs. Analysis of treatment effect was based on a comparable number of patients in both groups $(z=0.43$, $95 \% \mathrm{CI}=0.36-0.23, \mathrm{p}<0.66)$. Both groups were comparable in terms of baseline characteristics. The frequency and intensity of manic symptoms (MSRS score) in both groups decreased significantly from baseline to week 4 (Table 1). Improvement in the aripiprazole group seemed to be faster initially but was surpassed by that in the lithium group after a short period. In the aripiprazole and lithium groups, the intensity of manic symptoms decreased by $\geq 25 \%$ in 5 and 7 patients and by $>50 \%$ in 1 and 5 patients, respectively. Between-group analysis showed that lithium was more effective at weeks 3 and 4 in decreasing the frequency and intensity of manic symptoms (Table 1 ).

In repeated-measures ANOVA, the aripiprazole group showed significant decreases in the frequency of manic symptoms $(F(4,55)=2.37$, sum of squares $[\mathrm{SS}]=429.22$, mean squared error $[\mathrm{MSe}]=45.36, \mathrm{p}<0.05)$ but nonsignificant decreases in intensity of manic symptoms $(F(4,55)$ $=2.08, \mathrm{SS}=968.77, \mathrm{MSe}=116.18, \mathrm{p}<0.07)$, whereas the lithium group showed significant decreases in both frequency $(F(4,50)=3.75, \mathrm{SS}=1629.14$, MSe $=108.48$, $\mathrm{p}<0.009)$ and intensity $(F(4,50)=4.88, \mathrm{SS}=3264.97$, $\mathrm{MSe}=167.15, \mathrm{p}<0.002)$ of manic symptoms.

In split-plot (mixed) design ANOVA, the aripiprazole and lithium groups differed significantly in terms of frequency $(F(9,110)=2.67, \mathrm{SS}=8562.58, \mathrm{MSe}=356.31$, $\mathrm{p}<0.007)$ and intensity $(F(9,110)=2.80, \mathrm{SS}=8497.93$, $\mathrm{MSe}=337.74, \mathrm{p}<0.005)$ of the manic symptoms.

The lithium group achieved greater improvement in symptoms than the aripiprazole group in terms of BRMS score (decrease of $46.9 \%$ vs $26.6 \%$ ), SAI score (increase of $141.3 \%$ vs $27.3 \%$ ), and CGI-G (decrease of $28.5 \%$ vs 19.3\%) [Table 2].

The effect size was analysed in terms of decreases of the MSRS (frequency and intensity) scores at week 4 . It showed considerable improvement $(d \geq 0.8$ or $r \geq 0.3$ ) in both groups. The major adverse effects reported in the 
Table 1. Patient characteristics and improvement in the Manic State Rating Scale score in aripiprazole and lithium groups.

\begin{tabular}{|lcccccc|}
\hline Variable & $\begin{array}{c}\text { Aripiprazole } \\
(\mathbf{n = 1 2})^{*}\end{array}$ & $\begin{array}{c}\text { Lithium } \\
(\mathbf{n = 1 1})^{*}\end{array}$ & $\boldsymbol{t}$ & $\boldsymbol{d f}$ & $\begin{array}{c}\text { 95\% confidence } \\
\text { interval }\end{array}$ & p Value \\
Age, y & $30.66 \pm 10.37$ & $29.80 \pm 12.10$ & 0.211 & - & -7.57 to 9.30 & 0.83 \\
\hline Duration of illness, y & $5.86 \pm 3.96$ & $7.06 \pm 4.02$ & -0.823 & - & -4.19 to 1.79 & 0.41 \\
\hline No. of prior episodes & $3.93 \pm 2.20$ & $5.13 \pm 3.09$ & -1.223 & - & -3.21 to 0.81 & 0.23 \\
\hline Manic State Rating Scale score & & & & & & \\
Frequency & & & & & & \\
Week 0 & $78.51 \pm 12.63$ & $77.09 \pm 10.68$ & 0.29 & 21 & -8.77 to 11.61 & 0.77 \\
Week 1 & $74.19 \pm 8.71$ & $76.75 \pm 9.11$ & -0.68 & 21 & -10.29 to 5.17 & 0.49 \\
Week 2 & $72.79 \pm 9.48$ & $70.29 \pm 11.17$ & 0.580 & 21 & -6.46 to 11.46 & 0.56 \\
Week 3 & $70.16 \pm 10.92$ & $59.87 \pm 9.31$ & 2.42 & 21 & 1.45 to 19.13 & 0.02 \\
Week 4 & $68.77 \pm 9.72$ & $49.93 \pm 11.37$ & 4.28 & 21 & 9.69 to 27.99 & $<0.001$ \\
Intensity & & & & & & \\
Week 0 & $79.33 \pm 9.77$ & $82.18 \pm 10.30$ & -0.68 & 21 & -11.55 to 5.85 & 0.50 \\
Week 1 & $75.70 \pm 8.83$ & $80.24 \pm 9.83$ & -1.16 & 21 & -12.63 to 3.55 & 0.25 \\
Week 2 & $74.66 \pm 7.25$ & $76.53 \pm 8.72$ & -0.56 & 21 & -8.80 to 5.06 & 0.58 \\
Week 3 & $73.03 \pm 10.73$ & $59.97 \pm 9.81$ & 3.037 & 21 & 4.12 to 22.00 & 0.006 \\
Week 4 & $70.97 \pm 10.64$ & $43.12 \pm 9.17$ & 6.69 & 21 & 19.20 to 36.50 & $<0.001$ \\
\hline
\end{tabular}

Data are presented as mean \pm standard deviation.

Table 2. Improvement in MSRS, BRMS, SAI, and CGI-G scores in aripiprazole and lithium groups, with effect-size analysis.

\begin{tabular}{|c|c|c|c|c|c|c|c|c|}
\hline Outcome measure & Baseline $^{*}$ & Week $4^{*}$ & $t$ & $d f$ & $\begin{array}{c}95 \% \\
\text { confidence } \\
\text { interval }\end{array}$ & $\begin{array}{c}\mathbf{p} \\
\text { Value }\end{array}$ & $\begin{array}{c}\text { Cohen's } \\
\quad d\end{array}$ & $\begin{array}{l}\text { Effect } \\
\text { size } r\end{array}$ \\
\hline MSRS (frequency) aripiprazole & $78.51 \pm 12.63$ & $68.77 \pm 9.72$ & 2.117 & 22 & 0.20 to 19.28 & 0.04 & 0.86 & 0.39 \\
\hline MSRS (frequency) lithium & $77.09 \pm 10.68$ & $49.93 \pm 11.37$ & 5.77 & 20 & 17.35 to 36.97 & 0.000 & 2.46 & 0.77 \\
\hline MSRS (intensity) aripiprazole & $79.33 \pm 9.77$ & $70.97 \pm 10.64$ & 2.005 & 22 & -0.29 to 17.01 & 0.05 & 0.81 & 0.37 \\
\hline MSRS (intensity) lithium & $82.18 \pm 10.30$ & $43.12 \pm 9.17$ & 9.00 & 20 & 28.79 to 46.13 & 0.000 & 5.77 & 0.94 \\
\hline BRMS aripiprazole & $28.42 \pm 8.73$ & $20.86 \pm 10.11$ & 1.96 & 22 & -0.44 to 15.56 & 0.06 & 0.73 & 0.34 \\
\hline BRMS lithium & $29.16 \pm 9.16$ & $15.49 \pm 8.74$ & 3.58 & 20 & 5.71 to 21.63 & 0.001 & 1.52 & 0.60 \\
\hline SAI aripiprazole & $2.75 \pm 1.09$ & $3.50 \pm 0.83$ & -1.89 & 22 & -1.57 to 0.07 & 0.07 & -0.77 & -0.36 \\
\hline SAI lithium & $3.10 \pm 0.68$ & $7.48 \pm 1.13$ & -11.01 & 20 & -5.21 to -3.55 & 0.000 & 4.69 & -0.92 \\
\hline CGI-G aripiprazole & $4.57 \pm 1.22$ & $3.69 \pm 0.74$ & 2.13 & 22 & 0.03 to 1.73 & 0.04 & 0.87 & 0.39 \\
\hline CGI-G lithium & $4.78 \pm 0.92$ & $3.42 \pm 0.88$ & 3.54 & 20 & 0.56 to 2.16 & 0.002 & 1.51 & 0.60 \\
\hline
\end{tabular}

Abbreviations: BRMS = Bech-Rafaelsen Mania Scale; CGI-G = Clinical Global Impressions-Global Improvement scale $;$ MSRS = Manic State Rating Scale; SAI = Schedule for Assessment of Insight.

* Data are presented as mean \pm standard deviation.

aripiprazole group were inner unrest $(\mathrm{n}=4)$, mild stiffness $(n=3)$, and sedation $(n=3)$, whereas the major adverse effect reported in the lithium group was tremor $(n=5)$.
Post-hoc power analysis showed a power of 0.31 for the present assessment, which changed to 0.72 in compromised power analysis. 


\section{Discussion}

Many patients with bipolar disorder can recover a practical level of function between episodes, but approximately $30 \%$ of them have severe problems in occupation. There is a considerable gap between clinical recovery and functional recovery, particularly with respect to working recovery. This gap results in an inferior socioeconomic situation, despite similar levels of training, in comparison with the general population. ${ }^{2}$

Many randomised controlled trials have been conducted for newer anti-manic drugs, but they tend to report only satisfactory evaluation and conceal the outcomes of negative trials by not reporting expectable differences between an innovative treatment and placebo. This bias has possibly restricted or influenced the existing clinical data. ${ }^{18}$ Clinicians must be alert against generalisation of the conclusions to medical practice..$^{5}$ In our study, withingroup analysis showed that both aripiprazole and lithium were effective in the amelioration of manic symptoms, but between-group analysis showed that lithium was significantly more effective than aripiprazole. This finding was consistent with the non-significant improvement of intensity of symptoms by aripiprazole. The same inference remained consistent in terms of BRMS and SAI scores, although both groups achieved significant improvement in CGI-G score.

Nonetheless, two studies have reported comparable outcomes of aripiprazole and lithium for management of acute mania. ${ }^{11,12}$ In one of those studies, only 20 of 66 patients completed the entire treatment course. ${ }^{12}$ The $60 \%$ drop-out rate meant that there was insufficient statistical power to draw valid conclusions. In other studies, based on existing guiding principles, aripiprazole was considered a first-line alternative for the short-term management of mania, ${ }^{7,10}$ and as a first-line or second-line alternative for stopping the relapse of mood episodes in the course of longer-term treatment., ${ }^{7,19,20}$ Comparisons of aripiprazole with other medications are required to conclusively determine the position of aripiprazole in relation to other drugs. ${ }^{19}$ The existing evidence does not support the effectiveness of aripiprazole for management of bipolar depression and its relapse, ${ }^{21}$ which is possible with lithium. ${ }^{22}$ There are still too few studies comparing lithium with second-generation antipsychotics. ${ }^{5}$ Despite this lack of comparison studies, one study reported that antipsychotic drugs (haloperidol or second-generation antipsychotics) may have greater efficacy or faster action than mood stabilisers such as lithium, valproate, and carbamazepine..$^{18}$

In Europe, oral aripiprazole has been approved for treatment of moderate-to-severe manic episodes in adolescents with bipolar I disorder, but its long-term (over 30 weeks) effectiveness could not be verified owing to a high drop-out rate. ${ }^{10}$ In a double-blind study of 40 female in-patients with acute mania, both olanzapine and lithium were effective in improving manic symptoms, and lithium was significantly more effective than olanzapine..$^{23}$ In another study, both lithium and valproate were effective for improvement of manic symptoms, and lithium was significantly more effective than valproate. ${ }^{24}$ Many antimanic drugs are significantly more effective than placebo, but their comparable effect sizes and overlapping confidence intervals make it difficult to determine which is better. In addition, modern medical practice is also influenced by cost and time; regular use of a combination of antipsychotics and mood stabilisers to control symptoms as fast as possible is encouraged. ${ }^{18}$

It is important to emphasise the use of various outcome measures, analysis techniques, treatment durations and dosages, and sample sizes and patient cohorts (sex, age, duration of illness, number of episodes, smoking status, previous treatments, and pharmacology) in studying the treatment effect of any drug. Additionally, pharmacogenetic or ethnopsychopharmacologic differences between Western and Eastern populations may affect assessment outcomes.

Lithium is superior to second-generation antipsychotics $^{23}$ or mood stabilisers ${ }^{24}$ in decreasing the frequency and intensity of symptoms. Although lithium toxicity and its narrow therapeutic index may lead clinicians to opt for second-generation antipsychotics, monitoring of serum level of lithium and standard physical and laboratory examinations may modify doctors' perspectives towards lithium.

Our study has limitations, including a small sample size, short duration of evaluation, sex-based sampling, and exclusion of mixed episodes. Patients' treatment records should have been reviewed, and responses to lithium and second-generation antipsychotics should have been recorded.

\section{Conclusion}

Lithium is more effective than aripiprazole in improving manic symptoms.

\section{Acknowledgments}

The author gratefully acknowledges SJ Gholibeygi, S Akbari, P Dadkhah, N Rezvani, and the Department of Research, Razi Psychiatric Hospital for their practical and financial support.

\section{Declaration}

The author has no conflicts of interest to disclose.

\section{References}

1. Brown R, Taylor MJ, Geddes J. Aripiprazole alone or in combination for acute mania. Cochrane Database Syst Rev 2013;12:CD005000. Eross ret

2. American Psychiatric Association. Diagnostic and Statistical Manual of Mental Disorders. 5th ed. Washington, DC: American Psychiatric Association; 2013:123-32.

3. Kirino E. Profile of aripiprazole in the treatment of bipolar disorder in children and adolescents. Adolesc Health Med Ther 2014;5:211- 


\section{1. cross ret}

4. Sadock BJ, Sadock VA. Depression and Bipolar Disorder. In: Kaplan and Sadock's Synopsis of Psychiatry, 10th edition; 2007:536-62.

5. Tohen M, Vieta E. Antipsychotic agents in the treatment of bipolar mania. Bipolar Disord 2009;11(Suppl 2):45-54. Eross re

6. Sayyaparaju KK, Grunze H, Fountoulakis KN. When to start aripiprazole therapy in patients with bipolar mania. Neuropsychiatr Dis Treat 2014;10:459-70.

7. Dhillon S. Aripiprazole: a review of its use in the management of mania in adults with bipolar I disorder. Drugs 2012;72:133-62. Eross ref

8. Tsai AC, Rosenlicht NZ, Jureidini JN, Parry PI, Spielmans GI, Healy D. Aripiprazole in the maintenance treatment of bipolar disorder: a critical review of the evidence and its dissemination into the scientific literature. PLoS Med 2011;8:e1000434. Eross ret

9. Vieta E, Owen R, Baudelet C, McQuade RD, Sanchez R, Marcus $\mathrm{RN}$. Assessment of safety, tolerability and effectiveness of adjunctive aripiprazole to lithium/valproate in bipolar mania: a 46-week, openlabel extension following a 6-week double-blind study. Curr Med Res Opin 2010;26:1485-96. cross ret

10. McKeage K. Aripiprazole: a review of its use in the treatment of manic episodes in adolescents with bipolar I disorder. CNS Drugs 2014;28:171-83. Eross re

11. Keck PE, Orsulak PJ, Cutler AJ, Sanchez R, Torbeyns A, Marcus RN, et al. Aripiprazole monotherapy in the treatment of acute bipolar I mania: a randomized, double-blind, placebo- and lithium-controlled study. J Affect Disord 2009;112:36-49. cross ret

12. El-Mallakh RS, Marcus R, Baudelet C, McQuade R, Carson WH, Owen R. A 40-week double-blind aripiprazole versus lithium followup of a 12-week acute phase study (total 52 weeks) in bipolar I disorder. J Affect Disord 2012;136:258-66. cross re

13. Kumar A, Datta SS, Wright SD, Furtado VA, Russell PS. Atypical antipsychotics for psychosis in adolescents. Cochrane Database Syst
Rev 2013;10:CD009582. crossret

14. Beigel A, Murphy DL, Bunney WE Jr. The manic-state rating scale: scale construction, reliability, and validity. Arch Gen Psychiatry 1971;25:256-62. Eross re

15. Bech P, Bolwig TG, Kramp P, Rafaelsen OJ. The Bech-Rafaelsen Mania Scale and the Hamilton Depression Scale. Acta Psychiatr Scand 1979;59:420-30. Eross ret

16. David AS. Insight and psychosis. Br J Psychiatry 1990;156:798808. Eross re

17. Clinical Global Impressions. ECDEU Assessment Manual for Psychopharmacology. Guy W, ed, Rockville: US Department of Health, Education, and Welfare. DHEW Publication; 1976: 76-338.

18. Yildiz A, Vieta E, Leucht S, Baldessarini RJ. Efficacy of antimanic treatments: meta-analysis of randomized, controlled trials. Neuropsychopharmacology 2011;36:375-89. eross re

19. Yatham LN, Fountoulakis KN, Rahman Z, Ammerman D, Fyans P, Marler SV, et al. Efficacy of aripiprazole versus placebo as adjuncts to lithium or valproate in relapse prevention of manic or mixed episodes in bipolar I patients stratified by index manic or mixed episode. J Affect Disord 2013;147:365-72. cross ret

20. McIntyre RS. Aripiprazole for the maintenance treatment of bipolar I disorder: a review. Clin Ther 2010;32(Suppl 1):S32-8. Eross re

21. Yatham LN. A clinical review of aripiprazole in bipolar depression and maintenance therapy of bipolar disorder. J Affect Disord 2011;128(Suppl 1):S21-8. cross re

22. Harrison P, Geddes J, Sharpe M. Lecture Notes: Psychiatry. 10th Ed. United Kingdom: Wiley-Blackwell; 2010:100-1.

23. Shafti SS. Olanzapine vs. lithium in management of acute mania. J Affect Disord 2010;122:273-6. Eross re

24. Shafti SS, Shahveisi B. Comparison between lithium and valproate in the treatment of acute mania. J Clin Psychopharmacol 2008;28:71820. Eross re 